\title{
El derecho a la ciudad en Latinoamérica: agendas en tensión
}

\author{
The right to the city in Latin America: political agendas in tension
}

María Laura Canestraro, Melina Jakubowicz

mlcanestraro@gmail.com; melinajaku.92@gmail.com

CONICET, Grupo de Estudios Sociourbanos-Centro de Estudios Sociales y Políticos-Facultad de Humanidades/Universidad Nacional de Mar del Plata

Enviado 16/04/2021 - Aceptado 24/06/2021

Canestraro, M. L.; Jakubowicz, M. (2021). "El derecho a la ciudad en Latinoamérica: agendas en tensión". En Proyección: estudios geográficos y de ordenamiento territorial. Vol. XV, (29). ISSN 1852 -0006, (pp. 51 - 77). Instituto CIFOT, Universidad Nacional de Cuyo. Mendoza.

https://doi.org/10.48162/rev.55.009 


\section{Resumen}

La cuestión del derecho a la ciudad, que originariamente definiera Henry Lefebvre en 1968, fue (re)visitada por numerosos cientistas sociales. Hoy resurge con énfasis tanto desde el campo académico y de los movimientos sociales como desde las políticas públicas, que recogen varios de los postulados y los (re)interpretan poniendo en tensión algunos de los ejes que vertebran la noción originaria. Emerge así un concepto ambiguo e indistintamente utilizado por agendas progresistas; y conservadoras y antidemocráticas (Pérez Ahumada; 2015).

Nos proponemos recuperar algunos debates sobre el derecho a la ciudad en el contexto latinoamericano, problematizando en torno a las controversias que se generan entre sus principios subyacentes y los lineamientos generales de las agendas de organismos multilaterales que propician su efectivización en la región, concretamente en el caso de ONU-Hábitat.

Partimos del concepto originario y presentamos algunas revisiones, para luego centrarnos en discusiones regionales. Seguidamente, presentamos los ejes centrales de las reuniones del mencionado organismo: Hábitat I (1976), Hábitat II (1996) y Hábitat III (2016), deteniéndonos en la Nueva Agenda Urbana y sus recomendaciones a los Estados miembro, para ponerlos en diálogo con algunos indicadores recientes sobre cuestiones relevantes en la garantía del derecho a la ciudad.

Palabras clave: derecho a la ciudad - Latinoamérica - agendas urbanas

\section{Abstact}

The matter of the Right to the city, originally defined by Henry Lefebvre in 1968, has been (re) visited by many social scientists. Today, it reemerges with emphasis, not only from the academic and the social movement fields, but also from the field of policy making, that make their own reinterpretations of its postulates, creating a tension around the axles that gave shape to the original notion. Thus, a new concept emerges, one that is ambiguous and indistinctly used both by progressive and conservative anti-democratic agendas.

We set ourselves to recover some of these debates regarding the right to the city within the Latin-American context, and put in question the controversies that emerge between its underlying principles and the general guidelines of the multilateral international organizations' agendas that encourage its effective making in the region, more accurately, the case of UN-Habitat.

Our starting point is the original concept; we present some of its revisions and then move on to the regional debates. Then, we present the main topics of the aforesaid organization's meetings: Habitat I (1976), Habitat II (1996) and Habitat III (2016). We take a special interest in the New Urban Agenda and the recommendations made to the Member States, in order to start a dialogue with a few recent indicators about relevant matters to guarantee the right to the city.

Key words: right to the city -Latinamerica - Urban Agendas 


\section{Del concepto lefebvriano a las discusiones actuales}

En su origen, el concepto de derecho a la ciudad, que definiera Henry Lefebvre en 1968, remite al impacto negativo que aquel observa en las ciudades regidas por economías capitalistas, convertidas en mercancías al servicio de la acumulación privada. En palabras del propio Lefebvre, invita a pensar "la realidad urbana destinada a los usuarios, y no a los especuladores, a los promotores capitalistas, a los planes de los técnicos" (1968:51).

La producción del espacio capitalista barre con la ciudad anterior, dejando lugar a la hegemonía del valor de cambio. Así, "la ciudad, que era 'una obra' que unificaba lenguajes, códigos y tejidos sociales comunes, se convierte en 'un producto': 'la comunidad se desvanece, el vecindario se desmorona'" (Costes; 2011:91). Lefebvre se preguntaba si acaso la ciudad podía recuperar su capacidad para la integración y participación cuando habían sido casi totalmente eliminadas y concluía en que era la clase trabajadora la que, por entonces principal víctima de la segregación socio-espacial, debía encabezar ese proceso de cambio. En ese camino, llegaría el fin de la ciudad industrial y el advenimiento de una nueva realidad urbana (Costes; 2011). En la venidera sociedad urbana se produciría la reapropiación del hombre de sus condiciones de existencia en tiempo, espacio y objetos, en tanto valores de uso.

El pensamiento lefebvriano y el concepto de derecho a la ciudad tuvo una trayectoria zigzagueante (Molano, 2015). En los últimos años se ha renovado el interés por el tema tanto desde los movimientos sociales como desde el campo académico y de las políticas públicas urbanas, que recogen varios de los postulados centrales y los (re)interpretan, contradiciendo incluso algunos de los ejes que vertebran el concepto originario. Por eso mismo, se ha convertido en un concepto polisémico y en disputa (Carrión y Dammert, 2019).

En este debate emergente, algunos autores recuperan el concepto lefebvriano como oportunidad para crear espacios de democratización de las opiniones (Costes) y otros menos optimistas advierten acerca de la reapropiación burguesa del mismo (Merrifield) e, incluso, la cooptación y despolitización del proyecto lefebvriano por parte de gobiernos y organizaciones no gubernamentales que desconocen las implicancias del análisis original y utilizan en beneficio propio (Goonewardena) (citados en Molano, 2015).

Uno de los principales exponentes del debate actual es Harvey (2008), quien plantea que el derecho a la ciudad es más que la libertad de acceder a los 
recursos urbanos, en tanto se trata de un proceso de transformación del hombre, que se produce en simultáneo a la transformación de la ciudad. Por eso mismo, es un derecho común -antes que individual-, dado que "esta transformación depende inevitablemente del ejercicio de un poder colectivo para remodelar los procesos de urbanización" (Harvey, 2008: 23). Y agrega que es "el derecho de toda persona a crear ciudades que respondan a necesidades humanas. Todo el mundo debería tener los mismos derechos para construir los diferentes tipos de ciudades que queremos" (Harvey; 2010).

A su vez, Harvey expresa que en términos políticos el derecho a la ciudad es un significante vacío, en tanto su cualidad referencial depende de quiénes le otorguen un contenido específico (Pérez Ahumada; 2015). Con un matiz similar, Carrión y Dammert (2019) expresan que en tanto se moviliza entre distintos marcos discursivos, no tiene un principio de equivalencia legible, sea como concepto, idea o slogan. Aún en esa indefinición, afirman que se constituye como "un intento por modificar las condiciones "actuales" de producción de lo urbano, y generar condiciones que permitan un acceso equitativo o "justo" sobre este proceso y los bienes que produce" (2019: 12).

\section{Algunos ejes del debate (reciente) latinoamericano}

Sousa Santos (citado en Schiavo et al., 2015) considera que existe una disonancia entre la teoría crítica socio-política y las prácticas: mientras que la producción académica se desarrolla mayoritariamente en el Norte global, las iniciativas colectivas -sean organizadas o espontáneas-, suceden en el Sur global. En lo que sigue, recuperamos algunos exponentes del debate más reciente que representan una diversidad de enfoques en relación a la perspectiva lefebvriana y, a su vez, provienen de distintos países de la región, reflexionando mayoritariamente a partir de experiencias locales que ofrecen un panorama más acabado sobre la escala de análisis que hemos privilegiado.

En una perspectiva heredera del pensamiento lefebvriano, la brasileña Carlos (2005) manifiesta su preocupación por la ideologización del proceso que supone reflexión intelectual, movilización social y definición de políticas públicas disímiles, divergentes, no confluyentes-, y remite a los tres planos implicados en la discusión sobre el derecho a la ciudad: el de la práctica socio-espacial, el del Estado y el del conocimiento. Nos interesa aquí recuperar los dos primeros, que traccionan tanto en la definición como en la implementación de agendas. Desde la práctica socio-espacial, emergen los movimientos sociales: algunos orientados 
a la urgencia (vivienda, empleo); otros, cuestionando las políticas públicas y de planificación. En ese plano, se pone en jaque la contradicción fundamental de la producción del espacio urbano: su producción social y su apropiación privada. Además del espacio privado, el acto de habitar involucra una relación con los espacios públicos, para el encuentro, la sociabilidad. Sin embargo, dice Carlos, estos usos se ven restringidos por las necesidades de la reproducción ampliada del capital, que penetra sometiendo lugares a su funcionalización. La práctica del habitar visibiliza la separación/disociación de los elementos de la vida, en donde espacio y tiempo aparecen entrecortados, en fragmentos, por actividades divididas y circunscriptas. El derecho a la ciudad surge como necesidad, como negación de la fragmentación, de la imposibilidad de los habitantes de hacer uso de la ciudad, "demostrando la necesidad de la transformación radical de la ciudad que aparece y es vivida como pérdida y privación, extrañamiento y caos" (Carlos, 2005: 3). En el plano del Estado, se define la planificación a través de las políticas. Allí, el derecho a la ciudad se vincula con lo que el Estado está dispuesto a ceder para la gestión de la ciudad, teniendo así un entendimiento limitado del concepto: por ejemplo, como "el derecho a la vivienda más servicios", en el proceso de elaboración del Estatuto de la Ciudad. Bajo ese discurso, se esconde que ello no sucede sin la cooptación de los movimientos urbanos, que supeditan sus intereses a los del Estado y además que la producción del espacio gana un carácter estratégico, en donde el Estado logra imponer relaciones de producción a la sociedad a través de la dominación del espacio. Es ese proceso, el ciudadano se convierte en consumidor, de mercancías o de servicios públicos.

Por su parte, el colombiano Pradilla Cobos (2016) también desde una mirada crítica sobre el derecho a la ciudad en el contexto de la urbanización capitalista, pone el foco en los movimientos sociales y señala que los mismos han tenido un viraje en relación a sus consignas: de demandar suelo, vivienda y otras condiciones básicas para la reproducción de la fuerza de trabajo hacia el enfrentamiento a mega proyectos y megaeventos urbanos; de buscar la satisfacción de sus condiciones de subsistencia a defender la calidad de vida y el patrimonio de los propietarios urbanos ${ }^{1}$. Ello es un emergente del pasaje del

\footnotetext{
${ }^{1}$ Dice Pradilla Cobos "Un ejemplo paradigmático donde coexisten los movimientos urbanos populares y los de capas medias, han sido los suscitados por los procesos de cambio urbano realizados con motivo de megaeventos de ferias, exposiciones o deportivos regionales o mundiales; el caso reciente más importante se ubica en Brasil en la actualidad con las movilizaciones populares contra los desalojos o las intervenciones en las favelas, justificadas por la adecuación de las ciudades para la Copa Confederaciones de Fútbol (2013), la Copa Mundial de Fútbol (2014) y los Juegos Olímpicos en Río de Janeiro (2016), en particular la construcción de
} 
movimiento colectivo a la participación individualizada, atravesado por la popularización del discurso de la participación ciudadana que trajo consigo diversos desplazamientos: del movimiento popular al de los sujetos individualizados de cualquier clase social, en vistas a acumular capital político; y del movimiento urbano popular autónomo, movilizado por conflictos, a la participación institucionalizada, controlada y subordinada a agendas políticas; y, a su vez, el riesgo de que tal institucionalización quite legitimidad a los movimientos sociales populares (Pradilla Cobos; 2016).

En ese marco, el derecho a la ciudad es la demanda por convertir el acceso a todas aquellas condiciones esenciales para la reproducción social en la ciudad, particulares y generales; en un derecho social garantizado por el estado. Por tanto, con carácter inalienable y universal para los ciudadanos. Sin embargo, sostiene Pradilla, los derechos humanos - incluso los previstos en la Declaración Universal - son aún letra muerta en constituciones y leyes, dado que no están dispuestos a garantizarlos, porque ello va en contra del patrón de acumulación de capital que deja por fuera aquellos derechos que no impliquen una relación de mercado. En definitiva, dice Pradilla Cobos "el Derecho a la Ciudad se convierte en una demanda política, antineoliberal, anticapitalista, que habría que conquistar en la lucha político-social, en un objetivo de los movimientos sociales en su conjunto, dentro y fuera de los estrechos marcos institucionales que, por lo general, sólo los asumen como declaraciones formales, demagógicas en muchos casos, aún en los estados latinoamericanos, en el nivel nacional o local, que se definen como anti o no neoliberales" (2016:169). En definitiva, aquí hay una perspectiva emancipatoria del derecho a la ciudad, en consonancia con lo que planteaba Lefebvre.

A su vez, el trabajo del chileno Pérez Ahumada (2015) introduce en el debate el concepto de ciudadanía urbana, sustentado en los principios de consideración de la ciudad como posesión común primaria, por sobre el Estado-nación y de la creciente importancia del habitar como criterio central de membresía política. Recogiendo los ejes centrales del legado lefebvriano, Pérez Ahumada expresa que el derecho a la ciudad implica el derecho a la apropiación -usar, habitar y representar el espacio-, y el derecho a la participación-controlar el proceso de toma de decisiones en la producción social del espacio-. Supedita a este último

Puerto Maravilla, siguiendo el modelo de revitalización del frente marino de Barcelona, convertido en mercancía de importación. Es necesario señalar que este tipo de intervenciones están íntimamente ligadas al discurso ideológico neoliberal de la competitividad urbana y el sobredimensionado papel asignado en ella a los llamados iconos urbanos" (2016:163). 
el derecho a la centralidad urbana: la creación de una estrategia que posibilite una vida, en donde lo urbano -entendido como lugar de encuentro y prioridad de valor de uso-, encuentra su base morfológica y su realización practico-material (Pérez Ahumada, 2015). En ese recorrido sobre el concepto, destaca que el derecho a la ciudad lefebvriano emana de prácticas de transformación social llevadas a cabo en la cotidianeidad y, por tanto, es un derecho colectivo, no relativo a nuestra condición humana.

Por su parte, Pírez desde Argentina analiza el derecho a la ciudad postulándolo como componente central de la democracia de la ciudad; es decir, de "la capacidad de la configuración y funcionamiento urbanos de incorporar de manera equitativa a todos los grupos sociales que en ella residen" (Pírez, 2014: 1). Su formulación es parte de la consolidación de la modernidad, que supone la expansión de la noción de progreso como de ciudadanía universal (Devalle, 2004 citado en Pírez; 2014), ya sea real o potencial. Así entendido, el derecho a la ciudad se disputa en dos dimensiones. La primera ligada al derecho a los satisfactores (suelo, vivienda, servicios, etc.) basado en la contradicción entre mercantilización y acceso, que se define entre la necesidad de configurar una demanda solvente que se subordine al mercado y, con ello, a las relaciones de reproducción del capital; y la existencia de procesos de desmercantilización que habilitan, aunque sea de manera parcial, el asentamiento en la ciudad a partir del sometimiento, no al mercado, sino a las relaciones del poder que lo legitiman. La segunda hace lo propio con el derecho a la centralidad, esto es, a gozar de la totalidad de la riqueza que supone una ciudad (Pírez, 2014).

En tal sentido, dice Pírez, la noción se relaciona contradictoriamente con dos aspectos estructurales de la urbanización capitalista: la tendencia a su plena mercantilización y la apropiación privada del suelo. Si bien dentro de estas limitaciones estructurales se ha desplegado, por medio de políticas públicas redistributivas, la inclusión en el acceso al suelo y a los demás componentes del hábitat urbano, tal reversión ha impulsado una creciente mercantilización y/o remercantilización de la producción de la ciudad, que resulta tanto en la continuidad de las dificultades de acceso para la población de ingresos medios y bajos; como de la posesión de suelo urbano que se incorpora a nuevos proceso de producción orientados a la obtención de ganancias - tales como la 
renovación, la gentrificación, etc.- (Pírez, 2014) ${ }^{2}$. Desde este enfoque, el derecho a la ciudad constituye una demanda que, aun poniendo en evidencia las contradicciones estructurales, se inscribe dentro de un régimen democrático capitalista.

Con una impronta similar, Mathivet (2010) recupera la noción planteada por Harvey (2008) - esto es, el derecho a transformar la ciudad en algo radicalmente distinto - y considera que para conquistarlo es necesario, en primer lugar, difundirlo y, con ello, activar procesos de movilización social e incidir en la formulación de políticas públicas. "Ese proceso implica cambios estructurales profundos en los patrones de producción, consumo y en las formas de apropiación del territorio y de los recursos naturales" (Mathivet; 2010:27). Sostiene además que el proceso se ha venido desarrollando de manera amplia en América Latina, principalmente en Brasil, México y Ecuador ${ }^{3}$.

Ello implica la búsqueda de soluciones contra los efectos negativos de la globalización, la privatización, el aumento de la pobreza, la escasez de recursos naturales, etc. En definitiva, el derecho a la ciudad se constituye como una alternativa al desarrollo urbano basado en la mercantilización, y sus diversas consecuencias; que ha creado "ciudades sin ciudadanos" (Mathivet; 2010).

\section{Hacia la inclusión del Derecho a la Ciudad en las agendas internacionales: el caso de las Conferencias de la ONU- Hábitat}

Tal como hemos recapitulado en los apartados anteriores la noción de derecho a la ciudad ha sido reivindicada e incorporada en las agendas de múltiples actores vinculados a la producción urbana. En este sentido es que se ha convertido en un paraguas o abanico que incluye una diversidad de demandas urbanas insatisfechas - desde movilidad hasta servicios y viviendas -; como así también el reclamo por el acceso equitativo a la producción y apropiación de la ciudad; e incluso, ha sido pensado como un derecho humano universal.

En el marco de estas disputas los organismos multilaterales se configuraron como actores centrales, impulsando agendas programáticas y, con ello,

\footnotetext{
${ }^{2} \mathrm{~A}$ su vez, en esa mercantilización creciente de la ciudad - viabilizada por procesos de destrucción-creación Pírez (2014) distingue entre población solvente (clases medias) y población insolvente (sectores populares). La exclusión de esta última es condición de ese proceso, aunque las primeras tampoco se hallan exentas, sobre todo cuando su localización se convierte en obstáculo de aquel. Sin embargo, sí son diferenciales las condiciones sociales del derecho a la ciudad. El autor ejemplifica esas contradicciones a partir del análisis de dos situaciones: en el Conurbano Bonaerense y en la Ciudad Autónoma de Buenos Aires.

${ }_{3}$ El trabajo citado es parte de la introducción de una compilación realizada por la autora (junto a Ana Sugranyes) sobre diversas propuestas y experiencias ligadas al derecho a la ciudad en el mundo y en América Latina, en particular. El texto es una publicación de Habitat International Coalition (HIC) producida en el marco del V Foro Urbano Mundial de 2010.
} 
recomendaciones hacia los Estados para avanzar en la efectiva implementación de aquel derecho. En lo que sigue nos detenemos a analizar qué lugar ha ocupado en las agendas impulsadas desde la ONU-Hábitat (Hábitat I, Hábitat II y Hábitat III), cómo se concibe y qué lineamientos se realizan, haciendo especial hincapié en la Nueva Agenda Urbana, emergente de la última conferencia celebrada en 2016.

Hábitat I, celebrada en 1976 en Vancouver (Canadá), se constituyó como la instancia fundadora de lo que hoy se conoce como ONU-Hábitat, el centro de coordinación de todas las cuestiones relativas a la urbanización y los asentamientos humanos en el sistema de las Naciones Unidas. Desde esta primera edición, las conferencias Hábitat se realizan cada 20 años con el objetivo de promover el desarrollo de asentamientos humanos sostenibles en un contexto mundial de urbanización progresiva (Canestraro, Zulaica y Arenaza; 2019).

En paralelo, se llevó a cabo el Foro Hábitat, un encuentro entre organizaciones civiles, profesionales y académicas en torno a esta misma temática. Como resultado de estos encuentros se produjeron dos documentos: la Declaración de Vancouver sobre los asentamientos humanos y el Plan de acción. Asimismo, este encuentro contribuyó a la consolidación de la Coalición Internacional por el Hábitat, cuyos orígenes se remontan al comité de organizaciones no gubernamentales que se estableció tras la Conferencia de Naciones Unidas sobre el Medio Ambiente Humano en Estocolmo en 1972, y cuyo fin fue encargarse de la coordinación de las aportaciones de las ONG a la primera conferencia Hábitat (Rodríguez y Sugranyes, 2017).

En 1996, en Estambul (Turquía), se realizó Hábitat /l con el objetivo expreso de tratar dos temas de igual importancia a escala mundial: "Vivienda adecuada para todos" y "Desarrollo sostenible de los asentamientos humanos en un mundo en proceso de urbanización"4. Respecto del primer tema, estableció la necesidad imperiosa de garantizar el derecho a una vivienda segura y salubre y a los servicios básicos, entendiéndolos como indispensables para el bienestar físico, psicológico, social y económico del ser humano. Con respecto al segundo eje, consideró que el desarrollo sostenible de los asentamientos humanos combina el desarrollo económico, el social y la protección del medio ambiente, respetando

\footnotetext{
${ }^{4}$ Preámbulo Programa Hábitat II, Conferencia de las Naciones Unidas sobre los asentamientos humanos, Turquía 1996. Disponible en: http://habitat.aq.upm.es/aghab/
} 
plenamente todos los derechos humanos y las libertades fundamentales. Además, resaltó el rol fundamental de la democracia, el respeto de los derechos humanos, la transparencia, la representatividad y la rendición de cuentas en la gestión pública y la administración en todos los sectores de la sociedad, así como la participación efectiva de la sociedad civil, como pilares indispensables para el logro del desarrollo sostenible (Karol; 2016) ${ }^{5}$.

En 2015, la Asamblea General de Naciones Unidas aprobó la Agenda 2030 con 17 Objetivos de Desarrollo Sostenible (ODS) para el período 2016-2030, el número 11 apunta a lograr que las ciudades y los asentamientos humanos sean inclusivos, seguros, resilientes y sostenibles. La Conferencia Hábitat III, celebrada en 2016 en Quito (Ecuador), tiene como resultado la adhesión de los países miembro a la Agenda de Desarrollo Sostenible 2030, y más específicamente, la adopción de la Nueva Agenda Urbana como guía de acción para la consecución del Objetivo 11. Al respecto, Rodríguez y Sugranyes (2017) plantean que, a partir del 2013, quienes promovieron la Carta Mundial por el Derecho a la Ciudad (2005) iniciaron un lobby internacional para que Naciones Unidas incluyera su enfoque en los documentos tanto del ODS como de Hábitat III.

Hasta Hábitat III, el concepto de derecho a la ciudad no había sido incluido en las agendas programáticas resultantes de los otros encuentros. Sin embargo, tanto en la Agenda 21 como en los objetivos y bases para la acción de Hábitat II se encontraban esgrimidos los principios fundamentales que componen el corpus conceptual y normativo del derecho a la ciudad: participación ciudadana, transparencia en la gestión, democratización de la ciudad, inclusión participativa de las minorías, función social de la propiedad 6 , etc. Asimismo, las distintas redes y organismos internacionales abocadas a las temáticas de asentamientos humanos y vivienda habían venido desarrollando plataformas y documentos de trabajo con el fin de contribuir a una inclusión clara de este concepto en las agendas programáticas.

\footnotetext{
${ }^{5}$ Específicamente se acordaron siete compromisos y un plan de acción mundial, que estipulaban una serie de estrategias tendientes a lograrlos. Estos objetivos referían a: 1 . Vivienda adecuada para todos; 2. Asentamientos humanos sostenibles; 3. Habilitación de facultades y participación de actores clave públicos, privados y comunitarios; 4. Equidad de género; 5 . Financiamiento de la vivienda y los asentamientos humanos; 6. Cooperación Internacional, y 7. Evaluación de los progresos. Con la misma perspectiva, en el año 2000 Naciones Unidas adoptó los 8 Objetivos de Desarrollo del Milenio para el período 2000-2015 (Karol, 2016).

${ }^{6}$ Respecto de la función social de la propiedad, puede mencionarse como antecedente lo expuesto bajo "Estrategias para la aplicación del Plan de acción global" en la Declaración de Estambul, 1996 (Apartado 4.2, Hábitat II, 1996).
} 
Un antecedente fundamental en ese derrotero, fue la formulación de la Carta Mundial por el Derecho a la Ciudad, en el año 2004 en el Foro de las Américas, realizado en Quito, que contó con la participación activa de redes y organizaciones de la sociedad civil, tales como el Foro Nacional por la Reforma Urbana (FNRU) de Brasil, la Coalición Internacional para el Hábitat (HIC), el Frente Continental de Organizaciones Comunales (FCOC), la Primera Asamblea Mundial de Pobladores, por mencionar solo algunos. Específicamente la Carta giró en torno a tres ejes: el ejercicio pleno de la ciudadanía, la gestión democrática de la ciudad; y la función social de la propiedad y la ciudad ${ }^{7}$ A este Foro le sucedieron otras iniciativas similares, como el debate Políticas urbanas $y$ el derecho a la ciudad, organizado en 2005 por la UNESCO en colaboración con UN-Habitat, o la publicación en 2010 de Ciudades para tod@s. Por el derecho a la ciudad, propuestas y experiencias por parte de Habitat International Coalition, que reúne una serie de artículos vinculados a la problemática del derecho a la ciudad, tanto desde lo teórico como en relación a su efectivo ejercicio. Se destaca también la creación de la Plataforma Global por el Derecho a la Ciudad, en 2014, que se reconoce como articuladora de movimientos y organizaciones sociales, académicos, redes internacionales, defensores de derechos humanos, ONGs, gobiernos locales y otros para contribuir a la promoción, defensa y cumplimiento del Derecho a la Ciudad.

Concomitantemente, venía avanzando la emergencia de un nuevo paradigma de derecho urbanístico que brega por la materialización de una reforma urbana orientada por el principio del derecho a la ciudad (Fernandes; 1999; 2003, Rolnik; 1996) ${ }^{8}$, y en el que confluyen distintas experiencias - impulsadas y/o retroalimentadas - de las organizaciones y los movimientos sociales. Con ese trasfondo, se sancionaron diversos instrumentos normativos orientados por esos principios, destacándose los casos pioneros de Brasil y Colombia. En Colombia, la novedosa normativa, plasmada en la Ley № 388 de 1997, estipula diversas

\footnotetext{
${ }^{7}$ Ortiz Flores (2006) sostiene que "La iniciativa de formular esta Carta se orienta, en primer término, a luchar contra todas las causas y manifestaciones de la exclusión: económicas, sociales, territoriales, culturales, políticas y psicológicas. Se plantea como respuesta social, contrapunto a la ciudad-mercancía y como expresión del interés colectivo (...) Así, la Carta define este derecho como "el usufructo equitativo de las ciudades dentro de los principios de sustentabilidad, democracia, equidad y justicia social". De ahí que no se limite nuestra propuesta a una carta de derechos humanos en la ciudad, sino que se conciba como un instrumento capaz de promover y garantizar el derecho de todos a la ciudad, en sus múltiples dimensiones y componentes" (2006:3).

${ }^{8}$ Fernandes sintetiza en dos principios la consolidación legal y constitucional del derecho a la ciudad en los países latinoamericanos: 1) la función socio ambiental de la propiedad y de la ciudad, que supone el predominio del interés público sobre los intereses individuales y estatales; y 2) la indivisibilidad del derecho urbano y la gestión urbana, propiciando la transparencia la y participación, y el fortalecimiento de los gobiernos locales y las relaciones intergubernamentales (Levenzon; 2014).
} 
regulaciones en el valor del suelo para beneficiar a la comunidad en su conjunto. En Brasil, la aprobación de la Ley Federal № 10.257 en 2001, conocida como el Estatuto da Cidade, postula un viraje en la comprensión e interpretación del marco jurídico, consagrando nuevos derechos colectivos.

Con posterioridad, como sostiene Levenzon (2014), Ecuador es el primer país en explicitar el derecho a la ciudad como parte de sus derechos fundamentales en su Constitución de 20089. Luego, encontramos otros casos como Uruguay y El Salvador que han aprobado leyes de ordenamiento territorial, que se orientan también por un nuevo paradigma de derecho urbanístico rompiendo con el patrimonialismo tradicional ${ }^{10}$.

En el caso de Argentina, se destaca la constitución del Movimiento por la Reforma Urbana que realiza su primera declaración el 3 de octubre de 2005 y promueve la organización de un espacio colectivo y pluralista que lleve adelante la lucha por la reforma urbana, con la adhesión de organizaciones sociales de base territorial, instituciones sin fines de lucro, cooperativas, universidades públicas, organismos estatales en diferentes niveles, parlamentarios e internacionales. Ello deriva, en 2009, en la creación de Habitar Argentina. Iniciativa multisectorial por el derecho a la Tierra, la Vivienda y el Hábitat, con el objetivo de generar un marco normativo que garantice el derecho a la vivienda, la tierra y el hábitat para todos. En términos de avances legislativos, se destaca en 2012 la sanción de la Ley № 14.449 de Acceso Justo al Hábitat, de la provincia de Buenos Aires, que tiene como propósito la promoción del derecho a la vivienda y a un hábitat digno y sustentable a partir de cuatro principios rectores: el derecho a la ciudad y a la vivienda, la función social de la propiedad, la gestión democrática de la ciudad, y el reparto equitativo de cargas y beneficios (Canestraro; 2016). En su diseño y sanción fue vital el papel de aquel espacio y la presencia de las organizaciones que lo integran. Desde Habitar Argentina, en 2017, además se constituyó el Consenso Nacional para un Hábitat Digno que

\footnotetext{
${ }^{9}$ Allí define que tanto aquel como los derechos a la vivienda y al hábitat, al medio ambiente, se inscriben en el marco de los derechos del buen vivir, traducción de la expresión quechua "sumak kawsay". Además, vincula expresamente el disfrute de la ciudad de todos los ciudadanos con las exigencias de sustentabilidad, justicia social, respeto a las diferentes culturas urbanas y equilibrio entre lo urbano y lo rural (Levenzon; 2014).

${ }^{10} \mathrm{En}$ Uruguay, la Ley de Ordenamiento territorial y Desarrollo Sostenible, sancionada en 2008, plantea competencias e instrumentos de planificación, participación y actuación, guiando el proceso de ordenamiento del territorio hacia la consecución de objetivos de interés nacional y general y diseñando los instrumentos de ejecución de los planes y de actuación territorial. En El Salvador, se aprueba en 2011 la ley de Ordenamiento y Desarrollo Territorial que regula el uso del suelo y los instrumentos de planificación, programación, evaluación y de gestión territorial. Además, incorpora el derecho a la ciudad, introduciendo instancias de participación de la sociedad civil en la gestión (Levenzon; 2014).
} 
exige el cumplimiento de una serie de principios desde una perspectiva de derechos ${ }^{11}$.

Las recomendaciones realizadas por estas diversas redes y organismos, entre muchos otros, fueron recogidas y reformuladas para la redacción de la Nueva Agenda Urbana, promulgada en 2016 en el marco de Hábitat III. Sin embargo, Rodríguez y Sugranyes (2017) advierten sobre los temas que se perdieron entre los primeros textos del proceso preparatorio y el final de Quito; dejándose de lado también la revisión de los compromisos adquiridos por los Estados Miembros de las Naciones Unidas 20 años atrás.

\section{La Nueva Agenda Urbana}

La Nueva Agenda Urbana (NAU) es el documento resultante del encuentro de Hábitat III. En él, se delinean los ideales y principios bajo los cuales los gobiernos y organismos se comprometen a pensar la urbanización de las ciudades en pos de un desarrollo sustentable, como así también normas para su aplicación efectiva. Respecto del derecho a la ciudad, sostiene que "Compartimos el ideal de una ciudad para todos, refiriéndonos a la igualdad en el uso y el disfrute de las ciudades y los asentamientos humanos y buscando promover la inclusividad y garantizar que todos los habitantes, tanto de las generaciones presentes como futuras, sin discriminación de ningún tipo, puedan crear ciudades y asentamientos humanos justos, seguros, sanos, accesibles, asequibles, resilientes y sostenibles y habitar en ellos, a fin de promover la prosperidad y la calidad de vida para todos. Hacemos notar los esfuerzos de algunos gobiernos nacionales y locales para consagrar este ideal, conocido como "el derecho a la ciudad", en sus leyes, declaraciones políticas y cartas" (Nueva Agenda Urbana, p.5)

El apartado citado es la única ocasión en todo el documento donde se menciona el derecho a la ciudad como tal. Sin embargo, en múltiples pasajes del texto se hace referencia a algunos de los principios que rigen el corpus normativo del derecho a la ciudad, a saber: la gestión democrática, la función social de la

\footnotetext{
${ }^{11}$ A saber: 1) principios rectores para el diseño e implementación de políticas territoriales integrales; 2) políticas públicas de regulación y redistribución de rentas en los mercados de suelo; 3) regulación del mercado de alquileres; 4) producción social del hábitat; 5) seguridad en la tenencia y regularización de tierra urbana y rural; 6) procedimientos democráticos en casos de desalojos; 7) seguridad democrática para un hábitat digno; 8) participación y acceso a la información; y 9) acceso universal a los equipamientos sociales y servicios básicos (CELS, 2015). También desde Habitar Argentina se impulsaron diversos proyectos de ley ligados a Ordenamiento Territorial, Vivienda y Producción Social del Hábitat, Regularización Dominial y Regulación de Desalojos.
} 
propiedad, y la producción social del hábitat. En este sentido, se hace hincapié en la importancia de una gestión transparente; de un proceso democrático y participativo en las tomas de decisiones; de una ciudadanía informada y empoderada en estos procesos; en la elaboración de políticas e instrumentos que atiendan a las problemáticas de vivienda y acceso al espacio público, etc. Asimismo, se resalta la necesidad de fortalecer los gobiernos locales y subnacionales, con el objetivo de que estos cuenten con los recursos necesarios para tomar decisiones en función de las carencias y demandas específicas de cada jurisdicción, y para ofrecer alianzas más efectivas (y atractivas) con los sectores privados y con los organismos multinacionales, para de este modo agilizar las inversiones de capital. A su vez, se exhorta a la captura de las plusvalías urbanas por parte de las distintas escalas de gobierno, a la movilización de recursos endógenos, a fin de mejorar las condiciones financieras para el desarrollo urbano.

Desde una mirada crítica al proceso, Rodríguez y Sugranyes (2017) señalan que las ciudades no fueron protagonistas de la Conferencia, aun a pesar del sesgo urbano. En tal sentido, a diferencia de las ediciones de Vancouver y Estambul, las propuestas alternativas se vieron atomizadas, poniéndose el foco en la asistencia de funcionarios a actividades y exposiciones junto a representantes de la sociedad civil del establishment. Sumado a ello, Cohen (citado en Rodríguez y Sugraynes; 2017) considera que la NAU pone en evidencia la falta de liderazgo de ONU-Hábitat, en tanto representa a diversos grupos de interés que, junto a Estados miembro, proponen, negocian y aprueban un documento sin prioridades ni instrumentos claros para su implementación. En lo que hace específicamente al derecho a la ciudad, concluyen en que está incorporado a la NAU de manera imprecisa, redundando en dificultades para evaluar su cumplimiento. "Al diluirse entre tantos otros eslóganes urbanos de moda, se dificulta también el trabajo de construcción de las obligaciones de respetar, proteger y cumplir los derechos humanos al hábitat, incluyendo suelo, vivienda, energía, transporte, planificación urbana y función social de la ciudad, como una demanda social en el proceso de concreción de un derecho compuesto y emergente. Es un proceso largo, y solo a través de la lucha y la negociación se podrá avanzar hacia el derecho a la ciudad" (Rodríguez y Sugranyes; 2017: 200). 
En el año 2018 se publica Diálogos sobre ciudades sostenibles. La gobernanza urbana en el núcleo de la implementación del ODS11, documento redactado por ONU-Habitat, Ciudades y Gobiernos Locales Unidos (CGLU), y el Grupo de trabajo global de los gobiernos locales y regionales, que propone una revisión del ODS 11. En él, se realizan recomendaciones para la implementación efectiva de los principios de aplicación propuestos en la NAU, basados en un análisis de lo hecho hasta ese momento. La gobernanza urbana se presenta como la piedra angular sobre la cual construir ciudades equitativas, resilientes, seguras y sostenibles. Asimismo, reconoce que el derecho a la ciudad se encuentra en el corazón mismo de la gobernanza territorial urbana, y se lo presenta como la principal herramienta para "luchar contra la exclusión socio-espacial, promover la justicia social, integrar a los migrantes, prevenir la discriminación y la violencia urbana, proteger los derechos sociales, para asegurar la prosperidad y el bienestar" (p.23). En este sentido, reconoce que "se hace todavía necesario un mayor reconocimiento del Derecho a la Ciudad, y que se debe adoptar un enfoque basado en los derechos a lo largo de todo el proceso de implementación y seguimiento de los ODS. Así, propone cambiar el discurso hacia un derecho colectivo a vivir en ciudades inclusivas y justas, asegurando la inclusión y la participación" (p.24).

\section{Qué “dicen” los indicadores: los temas urgentes de las ciudades latinoamericanas}

De acuerdo a lo señalado por Rodríguez y Sugranyes (2017) al iniciar la preparación hacia Hábitat III se manifestó la intención de construir propuestas para evaluar los compromisos asumidos por los Estados en la Conferencia anterior (Estambul; 1996) y de los temas emergentes en las ciudades. Sin embargo, en el proceso de concertación algunos contenidos quedaron desdibujados $^{12}$. Entre ellos, destacan la ausencia de: la crítica a la mercantilización del suelo y la vivienda, las desigualdades en las ciudades y la insostenibilidad del modelo de urbanización.

En lo que sigue, rastreamos los datos que en los últimos años arrojan algunos indicadores ligados a esas problemáticas - producidos no sólo por la propia ONU

\footnotetext{
12 "Así, en el transcurso de dos años, entre el texto "Progresos logrados hasta la fecha en la aplicación del documento final de la segunda Conferencia de las Naciones Unidas sobre los Asentamientos Humanos (Hábitat II) y determinación de los problemas nuevos y emergentes del desarrollo urbano sostenible", elaborado al inicio de la primera PrepCom 2014, y el texto final de la Nueva Agenda, tal como fue publicado el 21 de noviembre de 2016, se fueron extraviando varios elementos de análisis y diagnóstico" (Rodríguez y Sugranyes; 2017:193).
} 
Hábitat sino también por el BID -, dado que ello nos puede ofrecer algunas reflexiones sobre las controversias observadas.

Claro que la utilización de indicadores estandarizados no resulta suficiente para pensar la totalidad de las dimensiones que componen el derecho a la ciudad; incluso, su construcción metodológica, su fiabilidad y su implementación pueden ser cuestionadas. Más aún, muchas variables de carácter cualitativo y de producción de normativa específica, no son contempladas en esta operacionalización. Sin embargo, este es el mecanismo que los propios organismos multilaterales proponen para medir el avance en los compromisos establecidos por parte de los Estados miembros. Como sostienen Reyers et al. (2017), la existencia de indicadores de desempeño resulta central, en virtud de la posibilidad de medir el grado de avance en materia de compromisos y objetivos asumidos por los Estados en los diversos ámbitos internacionales; y, en función de ello, priorizar las opciones de políticas públicas más efectivas y eficientes para lograr su cumplimiento.

En lo que sigue, nos aproximamos a las mediciones que realizan ambos organismos (ONU-Habitat y BID) vinculadas a los contenidos mencionados, teniendo en cuenta los datos disponibles.

El Programa de Ciudades Emergentes y Sostenibles (BID)

La metodología propuesta por el BID en el Programa de Ciudades Emergentes y Sostenibles (CES), supone la realización de un diagnóstico rápido basado en un paquete de 17 indicadores estandarizados para identificar los desafíos en la sustentabilidad de una ciudad, en sus tres dimensiones: sostenibilidad urbana; sostenibilidad medioambiental y cambio climático; y sostenibilidad fiscal y gobernabilidad. Luego del mismo, se realiza un Plan de Acción para atender aquellos aspectos priorizados por la evaluación. El Programa utiliza un sistema de semáforo, en el cual las temáticas más urgentes son marcadas en rojo, aquellas que requieren atención en amarillo, y las que dan en valores normales en verde. El sistema semáforo supone la comparabilidad con el resto de las ciudades en donde se ha aplicado este programa (BID 2013).

En función del diagnóstico realizado con base en esos indicadores estandarizados, y con datos obtenidos de Censos Nacionales y estadísticas oficiales de cada país, se desarrolla en conjunto con los municipios y alcaldías, y 
algunos actores locales, un Plan de Acción para cada ciudad involucrada en el Programa.

Si analizamos los Planes de Acción de algunas ciudades intermedias que forman parte del CES, podemos tener algunas aproximaciones al problema del acceso al suelo y la vivienda y respecto de la sostenibilidad del modelo de urbanización, haciendo especial hincapié en el uso del suelo y el ordenamiento territorial ${ }^{13}$. El criterio de selección de datos busca ser representativo de las condiciones heterogéneas de las ciudades latinoamericanas. Así, se incluyen ciudades con poblaciones entre 150.000 y 2 millones de habitantes, cuyas principales actividades económicas son diversas (ligadas, según el caso, a la actividad portuaria, agroexportadora, turística, de servicios). Finalmente, se contempla también el factor de extensión geográfica del territorio en cuestión, seleccionando ciudades que oscilan entre los $600 \mathrm{~km} 2$ y los $3500 \mathrm{~km} 2$ de extensión.

Como ejemplo, tenemos el caso de Cartagena (Colombia) donde el 37,9\% de viviendas por debajo de los estándares de habitabilidad (78.407 viviendas) ${ }^{14}$, aunque según el Censo Nacional realizado en 2018, el porcentaje asciende a $38,7 \%{ }^{15}$.

En Asunción (Paraguay), se observa el 9,6\% de viviendas por debajo de los estándares de habitabilidad. El déficit cualitativo, sin embargo, es del $40 \%{ }^{16}$. Su principal déficit se presenta en el uso del suelo, con un modelo expansivo de baja densidad $(30,2 \mathrm{hab} / \mathrm{Ha})$, y un crecimiento anual de la huella urbana de $5,4 \%$ en el período 1992-2002, y 2,2 entre 2002-2012. Este crecimiento acelerado e insostenible hacia los anillos del periurbano está propiciado por los bajos valores del suelo no urbanizado ${ }^{17}$.

\footnotetext{
${ }^{13} \mathrm{EI}$ índice de sostenibilidad urbana utilizado por el BID en su Programa de Ciudades Emergentes y Sostenibles supone una multiplicidad de indicadores que abordan diversas dimensiones, tales como la desigualdad urbana, la movilidad y el transporte, la competitividad de la economía, el empleo, conectividad, educación, salud, entre otros. Aquí nos detenemos en la dimensión de Uso del Suelo y Ordenamiento del Territorio, que comprende la densidad habitacional, vivienda, áreas verdes y la planificación urbana.

${ }^{14}$ Plan de Acción Cartagena Sostenible 2033: Resiliente, Incluyente y Competitiva, BID CES 2015, pp. 78-79.

${ }^{15}$ Resultados de Déficit habitacional con base en el Censo realizado en 2018, publicado en abril 2020. La actualización de la forma en que se calculan los indicadores de déficit habitacional sigue las recomendaciones internacionales y tienen un acompañamiento técnico de ONU-Hábitat, en alianza con el Ministerio de Vivienda y el Departamento Nacional de Planeación.

${ }^{16}$ Plan de Acción Asunción Sostenible, BID CES, 2012, pp.52-53.

${ }^{17}$ Idem, pp. 50-53.
} 
También la ciudad de Cuenca (Ecuador), un 12,3\% de viviendas por debajo de los estándares de habitabilidad ${ }^{18}$. A su vez, presenta desafíos en el uso del suelo por el crecimiento urbano de baja densidad. En el año 2002, la tasa media de crecimiento de la huella urbana era del 2,36\%; en el año 2005 del 1,57\%, y para el año 2010 del 4,12\%. Estas tendencias implican una huella urbana poco compacta y de baja densidad, que ha dado forma a un periurbano cada vez más extenso, fortaleciendo una tendencia de expansión hacia áreas vulnerables no aptas para la urbanización y un modelo insostenible en el largo plazo ${ }^{19}$.

En el caso de Valdivia (Chile), según el diagnóstico realizado por el CES-BID en el año 2015, 4\% de viviendas por debajo de los estándares de habitabilidad ${ }^{20}$; mientras que según el informe de la Fundación Vivienda (2018), basado en el Censo Nacional realizado en el año 2017 en Chile, son 4052 las viviendas con déficit, que representa un $1,16 \%$ del valor nacional. (Censo Nacional Chile 2017). También presenta desafíos en la expansión de la huella urbana, con un modelo de extensión de baja densidad $(56,6$ hab/Ha). La evolución del crecimiento de la huella urbana muestra un crecimiento constante, extensivo y de baja densidad, con un 1\% en 1994, 1,7\% en 2001, y 2,3\% en 2013. Asimismo, se observan urbanizaciones menores desconectadas del área urbana continua en zonas asociadas al desarrollo de nuevos barrios cerrados, y confinamientos de viviendas sociales, destinadas a la población de bajos ingresos, en otros sectores de la ciudad, contemplados en el Plan Regulador Comunal ${ }^{21}$.

En el área metropolitana de Bahía Blanca-Coronel Rosales (Argentina) se considera que un $11,5 \%$ del total de viviendas se encuentra por debajo de los estándares de habitabilidad. El déficit cuantitativo de vivienda es del $5 \%$. Se observa en las últimas décadas un crecimiento de la huella urbana por encima del crecimiento poblacional, indicando una urbanización fragmentada, dispersa y de baja densidad que se expande hacia las periferias. Respecto de la segregación socio-espacial en esta dinámica de urbanización, encontramos que: un $4,47 \%$ de la huella urbana (que alberga un $1,51 \%$ de la población total de la región) se encuentra en la periferia en barrios cerrados orientados a segmentos

\footnotetext{
${ }^{18}$ Plan de Acción, Cuenca Sostenible, BID CES, 2014-2019, p.23-25.

${ }^{19}$ Idem, p.13-15.

${ }^{20}$ Plan de Acción de Valdivia Sostenible, BID-CES, 2015.

21 Idem, p. 77-79.

22 Plan de Acción Bahía Blanca Coronel Rosales, BID CES, 2020, p.90-93.
} 
de ingresos altos. Un $41 \%$ de la población, correspondiente a los sectores medios, ocupa el $22 \%$ de la huella urbana ubicándose en el centro fundacional del área. Por otra parte, un $28 \%$ de la población, con ingresos bajos, se ubica en la periferia ocupando un $18 \%$ de la huella urbana; mientras que otro $14 \%$ de la población ocupa un $5 \%$ de la huella en asentamientos informales ${ }^{23}$.

Según el propio BID-CES, el crecimiento de la huella urbana observado en estos casos tiene relación directo con el aumento en la inequidad urbana (índice compuesto por indicadores de pobreza, segregación socio-espacial y desigualdad de ingresos), en tanto los patrones de crecimiento expansivos y con baja densidad poblacional ocurren por los altos valores del suelo urbanizado, expulsando a la población de más bajos recursos hacia las periferias no consolidadas. A su vez, las situaciones habitacionales deficitarias presentan una heterogeneidad en función de sus características, que no suelen ser identificados según sus componentes, sean cuantitativos y/o cualitativos (Di Virgilio y Rodríguez; 2018) ${ }^{24}$.

\section{El Índice de la Prosperidad Urbana (ONU-Hábitat)}

Los distintos países tienen metodologías propias de medición para dar cuenta de la situación de las ciudades desde una perspectiva multidimensional (Canestraro, Zulaica y Arenaza; 2019). Esto permite identificar oportunidades y áreas potenciales de intervención para que las ciudades transiten por un sendero de prosperidad (ONU-Hábitat, 2016a), definida como un estado de satisfacción socioeconómica unido a la realización de otras condiciones no materiales, que en conjunto brindan seguridad integral a las sociedades y a los individuos, en el presente, mediano y largo plazo (ONU-Hábitat, 2012). Con ese horizonte tomó impulso la utilización del Índice de la Prosperidad Urbana (CPI, City Prosperity Index, por sus siglas en inglés), creado en 2012 por iniciativa de Naciones Unidas para medir el progreso actual y futuro de las ciudades.

La construcción del índice de ciudades prósperas implica la medición de un conjunto de indicadores agrupados en seis dimensiones: 1) productividad; 2) infraestructura de desarrollo; 3) calidad de vida; 4) equidad e inclusión social; 5)

\footnotetext{
23 Idem, p 72-75.

${ }^{24}$ Siguiendo a Di Virgilio y Rodríguez (2018), el déficit cuantitativo incluye: viviendas de calidad material irrecuperable o crítica, o más de un hogar por vivienda, o núcleos familiares económicamente independientes en hogares hacinados, mientras que el déficit cualitativo abarca: viviendas de calidad material recuperable; 0 viviendas de calidad material aceptable, pero con algún nivel de hacinamiento y sin allegamiento de otros hogares o de núcleos secundarios económicamente independientes
} 
sostenibilidad ambiental; y 6) gobernanza y legislación urbana ${ }^{25}$. A su vez, cada una de ellas incluye subdimensiones, y dentro de éstas se incorporan indicadores específicos medibles y comparables. Actualmente, el CPI es utilizado en más de 300 ciudades en el mundo, buscando producir información y aportar soluciones a formas que resultan ineficientes, insostenibles y disfuncionales, tal como fueron planificadas muchas ciudades en el siglo pasado; en la región, se destaca la medición en México (ONU-Hábitat, 2016a) y Ecuador (ONU-Hábitat, 2016b).

Según ONU-Hábitat (2016a, 2016b), se considera que se constituye como un monitoreo de la Agenda 2030 para el Desarrollo Sostenible y de la Nueva Agenda Urbana. De hecho, en Hábitat III se realizó la presentación de los resultados de su aplicación en ciudades mexiquenses y ecuatorianas.

Sintéticamente, para México "El valor promedio total del CPI es de 54.3, de modo que el resultado total para México se considera moderadamente débil. Las dimensiones 02: Infraestructura y 04: Equidad e Inclusión Social son las que presentan los mejores resultados, siendo de 62.6 y 70.7 respectivamente. El primero corresponde con un factor moderadamente sólido, mientras que el segundo es suficiente para considerarse como un factor sólido. En segundo término, la dimensión 03: Calidad de Vida tiene un valor ligeramente inferior, al ser de 62.0 siendo un factor moderadamente sólido. Después se colocan las dimensiones 01: Productividad y 05: Sostenibilidad Ambiental, con valores de 57.3 y 46.7 respectivamente, siendo factores moderadamente débil y débil; finalmente, la dimensión 06: Gobernanza y Legislación Urbana, obtuvo la valoración más baja con un valor de 37.9, clasificándose como un factor muy débil (...)" También se consideran las particularidades para algunas ciudades en particular (Guadalajara, Monterrey, Culiacán, Aguascalientes, Ciudad Juarez, Tuxla, Acapulco, entre otras), aplicando la misma metodología (ONU-Hábitat; 2016a: 17).

\footnotetext{
${ }^{25}$ El Programa ONU-Hábitat postula que una ciudad próspera es aquella que desarrolla en forma equilibrada un buen desempeño en estas seis dimensiones (ONU-Hábitat, 2016a; 2016b): 1. Una ciudad productiva que contribuye al crecimiento económico, genera ingresos, provee trabajos decentes e igualdad de oportunidades; 2. Una ciudad con infraestructura suficiente y eficiente para proporcionar los soportes físicos adecuados para la movilidad, la productividad, la interconectividad y los servicios básicos a la población; 3 . Una ciudad con buena calidad de vida que brinda a todos los ciudadanos una vivienda adecuada y servicios básicos decentes, facilitando el acceso igualitario a los servicios sociales, bienes públicos y buenas condiciones ambientales; 4. Una ciudad equitativa e incluyente para asegurar la distribución equitativa y la redistribución de los beneficios de una ciudad próspera y reducir la incidencia de la pobreza y de los asentamientos precarios; 5 . Una ciudad ambientalmente sostenible que protege el ambiente urbano al tiempo que garantiza el crecimiento mediante el aprovechamiento sostenible de los recursos naturales; 6 . Una ciudad con buena gobernanza que permite la participación ciudadana, administra los recursos en forma transparente, fortalece la capacidad institucional y hace más eficiente la gestión regulada (Canestraro, Zulaica y Arenaza; 2019).
} 
Para el caso de Ecuador, se considera que "En el rango de prosperidad moderadamente sólida se ubican las ciudades que tienen entre 60 y 69 puntos de prosperidad, que es el caso de 3 ciudades que pertenecen a la Sierra central y sur y que apenas alcanzan a superar el límite inferior del rango: Cuenca, Ambato y Quito. En el rango de prosperidad moderadamente débil, entre 50 y 59 puntos, se encuentran 18 ciudades de la muestra que tienen una productividad baja, presentan problemas estructurales de desigualdad y pobreza y atienden escasamente a los componentes sociales (...). Finalmente, un grupo de 6 ciudades se ubica en el rango de ciudades con prosperidad débil, entre 40 y 49 puntos, lo que implica que tienen problemas estructurales e históricos y en ellas se evidencia desigualdad y pobreza, así como una baja productividad local (...) se caracterizan por una falta de diversificación productiva, altos niveles de pobreza, carencia de servicios y tasas de escolaridad más bajas. Los resultados del CPI para Ecuador dejan en general una expectativa positiva sobre las oportunidades que tienen las ciudades de mejorar la vida de sus habitantes" (ONU-Hábitat; 2016b: 59)

En ambas metodologías llama la atención que las problemáticas que, al decir de Rodríguez y Sugranyes, (2017) resultaran desdibujadas en el proceso preparatorio hacia Habitat III sean justamente las que emergen desde los diagnósticos de los organismos internacionales -mercantilización del suelo y la vivienda, las desigualdades en las ciudades y la insostenibilidad del modelo de urbanización-. En tal sentido, por ejemplo, valdría señalar que existe una marcada contradicción con la relevancia dada al suelo en los ODS y la agenda de ONU-Hábitat, componente que ha sido omitido en el análisis de los instrumentos de medición propuestos por las mismas agencias y organismos que impulsan dichas agendas (Canestraro, Zulaica y Arenaza; 2019). Siendo además que el problema del suelo constituye un eje nodal del acceso y la integración a la ciudad (Durand Lasserve, 1997); es decir, de la garantía del derecho a la ciudad y, en tal sentido, atraviesa transversalmente tanto las seis dimensiones que hacen a la "prosperidad urbana" como a los tres ejes de "sustentabilidad de la ciudad", por mencionar los propósitos de los indicadores construidos ${ }^{26}$.

\footnotetext{
${ }^{26}$ También Rodríguez y Sugraynes (2017) ponen énfasis en los retrocesos que se dieron entre las Agendas de Vancouver, de Estambul y de Quito con relación al problema del acceso al suelo. En tal sentido, en Hábitat II se planteó la necesidad de garantizar el acceso a la tierra como una de las prioridades centrales, por considerarse que "todos los gobiernos deben mostrar su determinación de promover una oferta de terrenos adecuada en el contexto de las políticas de uso sostenible de la tierra". Esto surge de la idea de que la falta de políticas de
} 
Además, en el caso de los diagnósticos del CES, se brinda a los gobiernos locales información privilegiada sobre la ciudad, obtenida de manera eficiente, transparente y metódica. Sin embargo, podríamos preguntarnos qué tan confiable o pertinente resulta la información derivada de la aplicación de estos indicadores si tenemos en cuenta su construcción metodológica (Zulaica y Tomadoni, 2011): han sido producidos para poder medir la evolución de una ciudad a lo largo del tiempo, y para comparar entre ciudades involucradas en el CES. Es en esta comparabilidad entre ciudades donde yace su mayor debilidad: por estar pensados en términos generales para todas las ciudades, no se tienen en cuenta las especificidades de cada objeto de estudio, dejando de lado dimensiones importantes (Jakubowicz, 2018).

Otro tanto sucede con la indefinición operativa del concepto de "prosperidad urbana" propuesto por ONU-Habitat, que trae consigo diversas interpretaciones que requieren de ajustes en la selección de indicadores, dado que no existen criterios universales y los objetivos de prosperidad pueden ser variables de acuerdo a diversos contextos sociales y escalas territoriales. En definitiva, es una categoría versátil, ambigua e idealizada, pudiendo dificultar el análisis de situaciones concretas y el diseño de políticas urbanas (Canestraro, Zulaica y Arenaza; 2019).

\section{Reflexiones finales}

Desde su origen hasta la actualidad, la noción de derecho a la ciudad ha sido revisitada, reivindicada e, incluso, incorporada a las agendas de múltiples actores vinculados a la vida urbana: movimientos sociales, gobiernos, organismos no gubernamentales, académicos, entre otros. Como dice Zárate (2011), tanto la reforma urbana como el derecho a la ciudad están presentes en marcos teóricos y legales y también como plataforma para la acción en distintas regiones del mundo, ya sea de manera explícita o implícita.

En ese derrotero han convivido diversas demandas: desde consignas emancipatorias hasta ligadas a necesidades insatisfechas, pasando por el reclamo por el acceso equitativo a la producción y apropiación de la ciudad y la pelea por su constitución como un derecho humano universal. Siendo así, podría decirse que - parafraseando a Harvey - resulta un significante vacío, en tanto su

ordenamiento territorial en zonas rurales y urbanas es una de las principales causas de desigualdad y pobreza (Canestraro, Zulaica y Arenaza; 2019). 
definición depende de quiénes le otorguen un contenido específico (Pérez Ahumada; 2015).

Aún dentro de esa indefinición específica podemos afirmar que, teniendo en cuenta los avances en la efectiva garantía del derecho a la ciudad en la región, su concepción se restringe a una versión relativamente limitada: Ecuador es el único país que le ha otorgado rango de derecho fundamental en su Constitución de 2008; luego, encontramos otros avances normativos de menor jerarquía, que plasman algunos principios rectores vinculados a aquel - por ejemplo, Brasil, Colombia, El Salvador, Uruguay, y, en Argentina, la provincia de Buenos Aires Con frecuencia esos procesos - tanto en su diseño como en su efectiva implementación - se ven traccionados por el accionar de los movimientos y las organizaciones sociales que pugnan por acceder a los satisfactores y a la centralidad de la ciudad, obturando la lógica mercantilizada (Pírez; 2014).

En paralelo, los organismos multilaterales vienen realizando sostenidamente un paquete de recomendaciones orientados a mejorar la calidad de vida en las ciudades, eje nodal del derecho en cuestión. De manera específica, hemos repasado el accionar de ONU-Habitat en ese sentido: los diagnósticos son variopintos y robustos, aunque no sólo presentan inconsistencias en su realización - centralmente, como hemos sostenido porque es necesario construir indicadores "localmente situados" y no universalmente estandarizados - si no que al plasmarse en recomendaciones parecieran quedar en letra muerta.

A su vez, hemos observado el comportamiento de algunos indicadores construidos en función de agendas programáticas de aquellos organismos puntualmente, CES/BID y Ciudades Prósperas/ONU-Hábitat). Por supuesto que la garantía del derecho a la ciudad no se agota en las mediciones de los indicadores, pero sí ello constituye un dato sumamente relevante para comprender cómo se problematiza y qué imbricaciones presenta tanto en relación al debate teórico como a los avances normativos. Es a esa intersección que pretendemos aportar desde estas líneas.

Coincidimos con Guillén Lanzarote (2011) respecto de que el concepto de derecho a la ciudad puede resultar difícil de definir en función de su falta de concreción y abstracción; de hecho, tal como sostiene Cohen, su incorporación misma a la NAU se realiza de manera imprecisa, redundando en dificultades para evaluar su cumplimiento. 
Mientras tanto la agenda del derecho la ciudad en Latinoamérica pendula controversialmente entre los diagnósticos y recomendaciones que los organismos multilaterales y los (posibles) avances que los Estados - en sus diversos niveles - realizan para efectivizar su concreción. Ambas instancias, tensionadas por los movimientos y las organizaciones sociales que orientan sus estrategias hacia la satisfacción de demandas que - lejos de enraizarse en una concepción radicalizada y emancipatoria del derecho a la ciudad - se constituyen como intersticios dentro de una lógica urbana mercantilizante, priorizando las necesidades humanas ligadas a la vida urbana.

Son las autoridades locales quienes tienen un rol protagónico como garantes y protectores de los derechos humanos en la ciudad (Guillén Lanzarote; 2011). Si bien la NAU reconoce el esfuerzo de gobiernos nacionales y locales "para consagrar este ideal", agregaríamos que es fundamental la escala local no sólo por su injerencia en la gestión urbana sino además porque resulta imprescindible para incorporar estrategias participativas concretas, prestando especial atención a que dicha participación no se institucionalice de forma que quite legitimidad a los movimientos sociales (Pradilla Cobos; 2016). Es en esos intersticios que avanzan ciertas experiencias orientadas a garantizar un acceso equitativo a la ciudad en nuestra región. 


\section{Referencias bibliográficas}

AGENDA 21. (1992). Cumbre para la Tierra, Río de Janeiro.

BID CES. (2013). Anexo 2: Indicadores de la Iniciativa de Ciudades Emergentes y Sostenibles, Guía Metodológica.

CANESTRARO M.L. (2016). Sobre el derecho a la ciudad y el acceso al suelo urbano. Reflexiones a partir de intervenciones estatales recientes (Mar del Plata, 2012-2015). Estudios Socioterritoriales. Revista de Geografía. CIG-IGEHCSCONICET/UNCPBA, número 20, julio-diciembre

CANESTRARO, M. L., ZULAICA, M. L. Y ARENAZA, M. S. (2019). Hacia la construcción de indicadores habitacionales: principios y criterios desde el enfoque de derechos. Revista Latinoamericana de Metodología de las Ciencias Sociales, 9(2), e062

CARLOS ANA FANI ALESSANDRI. (2005). La utopía de la "gestión democrática de la ciudad. Scripta Nova. Revista Electrónica De Geografía y Ciencias Sociales, Vol. IX, núm. 194 (01), Universidad de Barcelona.

CARRIÓN MENA, F., DAMMERT-GUARDIA, M. (Eds.) (2019). Derecho a la ciudad: Una evocación de las transformaciones urbanas en América Latina, Serie Movimientos sociales y territorialidades, CLACSO.

DECLARACIÓN DE ESTAMBUL SOBRE LOS ASENTAMIENTOS HUMANOS (1996) Conferencia de las Naciones Unidas sobre los Asentamientos Humanos, Estambul (Turquía),

DÉFICIT HABITACIONAL (2018), Resultados con base en el Censo Nacional de Población y Vivienda 2018, Colombia, Abril de 2020.

DI VIRGILIO M. Y RODRÍGUEZ M. C. (2018); "Hábitat, vivienda y marginalidad residencial", en Piovani J. I. y Salvia A. (coord); La Argentina en el siglo XXI: cómo somos, vivimos y convivimos en una sociedad desigual. Encuesta Nacional sobre la Estructura Social; Siglo Veintiuno Editores Argentina; Ciudad Autónoma de Buenos Aires; pp. 183-220.

FUNDACIÓN VIVIENDA (2018), Déficit Habitacional Cuantitativo, Censo Chile 2017, Publicación № 5 
GUILLÉN LANZAROTE A. (2011). El derecho a la ciudad, un derecho humano emergente. En: Insititut de DretsHumans de Catalunya Serie Derechos Humanos Emergentes 7: El derecho a la ciudad, Barcelona;

GUIMARAES, R. (2003). Tierra de sombras: desafíos de la sustentabilidad y el desarrollo territorial y local ante la globalización corporativa. Santiago de Chile: Serie medio ambiente, División de Desarrollo Sostenible y Asentamientos Humanos $N^{\circ} 67$, CEPAL

JAKUBOWICZ, M. (2018). Accesibilidad simbólica al espacio público en la ciudad mercantilizada. Estudio de caso sobre Calles para la gente 2012-2018, Tesis de Licenciatura en Sociología. UNMDP.

LEVENZON, F (2014). El derecho a la ciudad y reformas legales en Argentina y América Latina. XI Simposio de la Asociación Internacional de Planificación Urbana y Ambiente (UPE 11), FAUD, La Plata.

MATHIVET, C. (2010). El derecho a la ciudad: claves para entender la propuesta de crear. Otra ciudad posible. En Sugranyes, A. y Mathivet, C. (eds.), Ciudades para tod@s. Por el derecho a la ciudad, propuestas y experiencias. Santiago de Chile: Habitat International Coalition.

MOLANO, F. (2015). El Derecho a la Ciudad en la ciudad neoliberal: una agenda estratégica para la lucha por la ciudad", mimeo. Disponible en https://derechoalaciudadflacso.wordpress.com/2015/05/22/el-derecho-a-laciudad-en-la-ciudadneoliberal-una-agenda-estrategica-para-la-luchaurbana\%e2\%80\%8f/ (consultado 29/05/2015)

NUEVA AGENDA URBANA. (2016), Conferencia de las Naciones Unidas sobre la Vivienda y Desarrollo sostenible, ONU Hábitat III, Quito.

ONU-HÁBITAT. (2018). Diálogo sobre ciudades sostenibles: La gobernanza urbana en el núcleo de la implementación del ODS 11, Informe Final, Estrasburgo, Francia, Mayo, Primer foro de gobiernos locales y regionales.

2016a . Índice de Prosperidad Urbana en la República Mexicana. México: ONU-Hábitat. 
2016b. La prosperidad en las ciudades de Ecuador: Primer reporte del Índice de Prosperidad Urbana (CPI) para 27 ciudades ecuatorianas. Quito: ONU-Hábitat - Banco de Desarrollo de América Latina.

2012. State of the world's cities 2012/2013: Prosperity of cities. New York: ONU-Hábitat.

ORTIZ FLORES E. (2006). Hacia una carta por el Derecho a la Ciudad, Coalición Internacional para el Hábitat.

PÉREZ AHUMADA M. (2015). Ciudadanía urbana y derecho a la ciudad: hacia una política del habitar. En: Reapropiaciones de Henri Lefebvre: Crítica, Espacio y Sociedad Urbana (Gásic I, Narváez A y Quiroz R. comps); 1era ed. Santiago de Chile, Ed. Triángulo

PÍREZ P. (2014). (con la colaboración de N. Cosacov): El derecho a la ciudad y la reestructuración neoliberal en Buenos Aires: movilizaciones de sectores populares ("insolventes") y clases medias ("solventes"): ¿Una extensión conceptual?. En: Seminario Construcción de Ciudadanía y Nuevos Actores en las Grandes Ciudades, México, Centro de Investigaciones Interdisciplinarias en Ciencias y Humanidades-UNAM.

PLAN DE ACCIÓN ASUNCIÓN SOSTENIBLE, BID CES (2012)

PLAN DE ACCIÓN BAHÍA BLANCA CORONEL ROSALES, BID CES, (2020)

PLAN DE ACCIÓN CARTAGENA SOSTENIBLE 2033: Resiliente, Incluyente y Competitiva, BID CES (2015)

PLAN DE ACCIÓN VALDIVIA SOSTENIBLE, BID CES, (2015)

PLAN DE ACCIÓN, CUENCA SOSTENIBLE, BID CES, (2014-2019)

RODRíGUEZ, A. Y SUGRAYNES, A. (2017). La Nueva Agenda Urbana: pensamiento mágico, Revista Vivienda y Ciudad - ISSN 2422-670X - Volumen 4 - Diciembre 2017

SCHIAVO, E., VERA P. Y GELFUSO A. (2015). El derecho a la ciudad entre el capitalismo actual y la apropiación de su significado. En I Congreso Latinoamericano de Teoría Social; Buenos Aires. 